\title{
Joining psychiatric care and faith healing in a prayer camp in Ghana: randomised trial ${ }^{\dagger}$
}

\author{
A. Ofori-Atta, J. Attafuah, H. Jack, F. Baning, R. Rosenheck and the Joining Forces Research Consortium
}

\section{Background}

Care of people with serious mental illness in prayer camps in low-income countries generates human rights concerns and ethical challenges for outcome researchers.

\section{Aims}

To ethically evaluate joining traditional faith healing with psychiatric care including medications (Clinical trials.gov identifier NCT02593734).

\section{Method}

Residents of a Ghana prayer camp were randomly assigned to receive either indicated medication for schizophrenia or mood disorders along with usual prayer camp activities (prayers, chain restraints and fasting) ( $n=71)$; or the prayer camp activities alone $(n=68)$. Masked psychologists assessed Brief Psychiatric Rating Scale (BPRS) outcomes at 2, 4 and 6 weeks. Researchers discouraged use of chaining, but chaining decisions remained under the control of prayer camp staff.

\section{Results}

Total BPRS symptoms were significantly lower in the experimental group ( $P=0.003$, effect size -0.48$)$. There was no significant difference in days in chains.

\section{Conclusions}

Joining psychiatric and prayer camp care brought symptom benefits but, in the short-run, did not significantly reduce days spent in chains.

\section{Declaration of interest}

None.

\section{Copyright and usage}

(c) The Royal College of Psychiatrists 2018
Ghana is a low-income country of 25 million people whose professional mental health needs are addressed by only 25 psychiatrists, 30 clinical psychologists and 900 psychiatric nurses. ${ }^{1,2}$ Most people who need care seek it from traditional, or faith-based healing institutions, ${ }^{3-5}$ primarily evangelical religious centres that offer residential care in sanitorium. These faith-based healing centres have come under scrutiny for human rights violations, such as forced fasting, prayer and the use of chain restraints. ${ }^{6,7}$ Conducting research in a context where human rights violations occur poses ethical challenges for researchers who must seek to maximise health benefits while minimising human rights violations. In this context demanding abrupt elimination of human rights abuses would preclude both providing potential health benefits to research participants and generating needed policy-relevant knowledge. Belief in supernatural or spiritual causes of mental illness is common in Ghana, and consequently people seek care from traditional healers or evangelical pastors. ${ }^{8-11}$ Recent legislation (Mental Health Act 846, 2012) seeks to expand access to psychiatric care, protect patients' rights and augment community-based services. The Act created a mental health authority for whom one initial priority is the improvement of care in prayer camps, although this aspect of the law has yet to be implemented. One approach to improving care in prayer camps is the addition of modern psychiatric care including pharmacological treatments. Such a collaboration has never been evaluated. $^{12}$

To evaluate the feasibility and effectiveness of such a collaboration, we conducted a randomised clinical trial (RCT) of psychiatric care, including pharmacotherapy, for several indicated diagnoses, provided by a team of mental health professionals in a prayer camp near Accra, Ghana. We sought to determine the benefit of a psychotropic drug intervention compared with usual care for people with mental disorders in a prayer camp setting in which the effectiveness of medication might be attenuated because: (a) caregivers do not believe in biomedical treatment; (b) chaining

† See editorials, pp. 6-8 and 9-10, this issue. and fasting add countertherapeutic stress; and (c) people with mental illness are stigmatised by residential segregation. We hypothesised that, even in a prayer camp setting, outcomes would be superior with pharmacotherapy as assessed by masked psychologist ratings of psychiatric symptoms on the Brief Psychiatric Rating Scale (BPRS). ${ }^{13}$ Secondary outcomes included patient self-report of symptoms and quality of life, and the number of days with any time spent in chains. We believed the ethical conduct of the study would bring benefits to study participants and improve future medical care in prayer camps, ultimately contributing to the reduction of human rights abuses.

\section{Method}

\section{Study design and setting}

The study was an open RCT with masked assessments comparing prayer camp care plus psychiatric/psychopharmacologic treatment supported by nurse clinical oversight with prayer camp care alone for a diverse set of medication sensitive conditions (Clinical trials. gov identifier NCT02593734). Mount Horeb is an Evangelical Pentecostal prayer camp with a 2012 mission statement promising to 'set free those held captive by Satan...through its ministry of fasting and prayer. ${ }^{14}$ A separate set of buildings referred to as 'the sanitarium', provide a residence for people with serious behavioural disturbances (see online supplement DS1 for details of the establishment of the collaboration (available at https://doi.org/10.1192/bjp. 2017.12)).

\section{The clinical/research team}

Psychiatric care was provided by a psychiatrist and psychiatric residents, and a community mental health officer (CMHO) - a nurse aid, and other staff supported study implementation and research data collection. The entire research team comprised three clinical psychologists, two psychiatrists, three residents in psychiatry, a research officer and a CMHO. 


\section{Recruitment}

For 2 years from July 2013, all sanitarium residents were evaluated by a psychiatrist or resident and also given a physical health evaluation. Although sanitarium admissions were voluntary, as far as the investigators were aware, it is possible that some participants were persuaded, coerced or cajoled by their families to enter the prayer camp. When participants were deemed unable to respond to questions, their family members/caregivers were interviewed for documentation of basic information.

The description of the study and all measures were translated into Twi (the most widely spoken Ghanaian language) and back translated to English to check for accuracy. Study information was read to potential study participants (many were illiterate), and informed consent was indicated by signing or thumb-printing directly, or through a family proxy. Families were called by phone and researchers conducted the full informed consent procedure with explicit assurance that their decision would not affect how their relative was treated. The study was approved by the ethics board of the Noguchi Memorial Institute for Medical Research, University of Ghana, which follows international standards (see online supplement DS1 for discussion of ethical considerations).

After providing consent, baseline assessments were completed, random assignment performed (as described below) and treatment initiated. The intervention was delivered over a 6-week period with masked assessments administered by trained psychologists 2, 4 and 6 weeks after randomisation. Masked assessors worked in a clinical setting that was set apart from the rest of the prayer camp to preserve the masking. The last assessment was completed in May of 2015.

\section{Eligibility and exclusion criteria}

Participants were considered eligible if they were already resident at the sanitarium and the psychiatrist determined that they met ICD-10 criteria for schizophrenia/schizoaffective disorder, a mood disorder (bipolar or major affective disorder) or another psychiatric disorder that was judged to be appropriately and safely treatable with available antipsychotic or antidepressant medication. ${ }^{15}$ Participants had to be $18-65$ years old and spoke English and/or Twi.

Participants were excluded if they had a physical health condition (such as malaria) that would make the use of study medication ineffective or unjustifiably risky by the judgement of the physician; if they were already taking psychotropic medication; did not intend to remain in the sanitarium for the duration of the trial; or if neither they nor their next of kin consented for participation.

\section{Intervention}

Clinically indicated medications available from the Ghana Health Service were prescribed by the psychiatrist/senior medical officers at doses they judged appropriate. Available antipsychotics included olanzapine, risperidone, haloperidol, chlorpromazine, and fluphenazine (oral and long-acting injectable). Available anti-depressants included fluoxetine and amitriptyline while the one available mood stabilizer was carbamazepine. Diazepam was available to calm very disturbed and disruptive patients. Also available were benztropine and trihexyphenidyl for extrapyramidal side-effects. Patients receiving medication were assessed daily by the CMHO (a nurse) who administered medications and evaluated side-effects and serious adverse events. After completing the study, the patients in the intervention group were given the option of continuing medication if recommended by the physician. Those in the control group were offered a 6-week trial of indicated medication.
All participants in the study received usual prayer camp treatment, which included a combination of prayer and Bible study, and fasting for 3-21 days when first admitted and before participation in the study. Fasting involved eating only one meal of sweetened light corn porridge and snacks of sugar cane each day.

\section{Use of chains}

As was the long-standing custom in the prayer camp, residents who were agitated, or considered at high risk for harming themselves or others, or leaving without informing staff, were shackled by sanitarium staff using a chain of approximately $0.6[\mathrm{th}] \mathrm{m}$ (2[th]feet) in length that was fastened around one leg and anchored to the concrete floor. Sanitarium staff brought food and water to the participants while they were chained and helped them with personal hygiene. Research staff did not play any role in the chaining. However, they monitored patients and often prompted staff to review the need for chains in both treatment groups. Unchained patients could walk around the prayer camp, attend church services and visit the neighbouring town or watch television.

Unchaining occurred when sanitarium staff thought that a participant no longer needed to be restrained as determined entirely by prayer camp staff. It was hoped that once the sanatorium staff observed clinical improvement, the use of chains would decline (see online supplement DS1 for interactions concerning chaining).

\section{Randomisation}

Randomisation was conducted using a card sorting method off site at the University of Ghana medical school and communicated by telephone. Cards were shuffled and the pack cut in two arbitrarily. The top card in the lower half was selected and if red, the next study participant was assigned to the intervention group and if black, to the control group. If patients in the control group were in urgent need of medication they were treated as medically necessary.

\section{Measures}

The primary outcome was the assessment of psychiatric symptoms with the 24 -item Brief Psychotic Rating Scale (BPRS), ${ }^{13}$ administered by trained, masked psychologists every 2 weeks for 6 weeks. Four BPRS subscales address thinking disturbance, hostility/ suspiciousness, withdrawal/retardation and anxiety/depression. Secondary measures included the 18-item version of the Brief Symptom Inventory (BSI), ${ }^{16}$ which is a measure of subjective distress; the Patient Health Questionnaire (PHQ-9), ${ }^{17}$ a 9-item depression scale; and the global quality of life item from the Lehman Quality of Life Interview (for example How would you rate your life overall on a scale from 1 , terrible to 7 , delighted?). ${ }^{18}$ The $\mathrm{CMHO}$ documented the number of days each patient spent in chains during each 14-day period. The treating psychiatrist recorded un-masked assessments using the Global Assessment of Functioning $(\mathrm{GAF})^{19}$ a 1-100 scale of severity of mental illness ranging from 0 (cannot be rated) to 100 (perfect health). ${ }^{20}$

A pilot study evaluated the self-report based BSI for use as the primary outcome measure, but some patients were too confused to offer coherent responses and/or did not readily understand the Likert-scale response format. The BPRS was therefore substituted as the primary outcome measure because ratings were based on staff judgements. Didactic and experiential training on the BPRS were provided at the prayer camp by R.R. before the study began.

Side-effects were assessed among patients in the intervention group by the treating nurse using the Udvalg for Kliniske Undersøgelser (UKU) side-effects rating scale. ${ }^{21}$ Side-effect assessment of patients not treated with medication was not possible 
because of limited CMHO time, but data were compared with published data on UKU side-effects in patients with schizophrenia. ${ }^{22}$

\section{Withdrawal from the study}

Sanitarium staff or a doctor (in the case of adverse effects) could request withdrawal of a participant from the study at any time. Participants could also ask to be withdrawn. If a patient in the intervention group left the prayer camp and chose to continue taking the medication, they were referred to a community psychiatric nurse, medical or psychiatric facility near their home. If the physician decided a patient in the control group could not be ethically cared for without medication, they were prescribed appropriate drugs, but data collection continued to support the intent-to-treat analysis. Patients who completed the study in either group were also referred for continued pharmacotherapy if they so desired.

\section{Data management and data analysis}

All completed forms were sent to the data management team (J.A.) for entry into an SPSS database. Chi-square and $t$-tests and were used to identify baseline differences between participants with 6week outcome data and those lost to follow-up. The primary outcome measure was the average of items in the BPRS total score measured at 6 weeks after randomisation (range 1-7 with higher scores indicating more severe symptoms) in an intention-to-treat analysis. The significance of difference between groups was evaluated at baseline and at 2, 4 and 6 weeks with $t$-tests. Effect size was evaluated by Cohen's $d$, the difference in group means divided by the pooled standard deviation. ${ }^{23}$

A repeated-measures mixed-effects model with a random intercept was used as a supportive analysis to compare group outcome differences from baseline to 6 weeks. The model included fixed effects for treatment group at baseline, treatment group at followup, time (a categorical variable) and the interaction of treatment at follow-up with time, with individual patients treated as random effects.

Analysis of secondary outcomes applied the same $t$-test and mixed-model strategies to the BPRS and subscales, BSI total score, Lehman Quality of Life global score, PHQ-9, number of days in chains in the previous 14 days, and GAF as rated by the unmasked prescribing psychiatrist. An additional secondary analysis was conducted among the subgroup diagnosed with schizophrenia, comparing groups on the BPRS total score and subscales, the BSI, PHQ-9 and Lehman scale at 6 weeks. Power analysis for the primary outcome suggested that the study would have $94 \%$ power to detect a 0.3 effect size (lower than the expectable 0.50 effect for psychotropic medications in an efficacy study) with a sample of 135 , allowing for $20 \%$ attrition.

\section{Results}

\section{Characteristics of sample}

Altogether 235 potential participants were screened of whom 150 were eligible; 143 gave informed consent and 7 refused (Fig. 1). There were 71 randomised participants in the intervention group and 68 in the control group (total $n=139$ ). The mean age of the sample was approximately 33 years with $67 \%$ male (Table 1 ). There were no statistically significant differences between groups at baseline (Table 1).

The most frequent diagnosis was schizophrenia/schizoaffective disorder followed by bipolar disorder and major depressive disorder with no significant differences between groups (Table 1). The total number of patients diagnosed with the primary target conditions (schizophrenia, bipolar disorder or major depressive disorder) was $97.2 \%$ of the experimental group and $89.6 \%$ of the control group. Mean score on the GAF was 34.2, reflecting 'some impairment in reality testing or communication (e.g., speech is at times illogical, obscure, or irrelevant) or major impairment in several areas'. BPRS symptom ratings averaged in the $2-3$ point range suggesting mild levels of symptom severity.

\section{Treatment}

Within the intervention group 63/71 (88.7\%) received psychotropic medication during the trial as compared with $11 / 68$ (16.2\%) of controls. The intervention group had a mean of 3.04 psychiatrist visits (of a possible four visits) and the controls had a mean of 2.79 of four visits. Patients in the intervention group were far more likely to have been treated with medications in every category especially antipsychotics (at $86.5 \%$ of visits as compared with $15.7 \%$ of visits for controls) (Table 2). Haloperidol and olanzapine were the most frequently prescribed antipsychotics. Doses among those receiving antipsychotic medication were generally similar between the groups (see footnote to Table 2).

\section{Outcomes}

Altogether 57 (80.3\%) participants in the intervention group and 53 controls $(77.9 \%)$ were assessed at 6 weeks $\left(\chi^{2}=0.12\right.$, d.f. $=1, P=$ $0.73)$. Those who were lost to follow-up at 6 weeks had significantly higher baseline symptom ratings than those with 6-week follow-up data on the BPRS anxiety/depression subscale and on the BSI but not on other measures.

On the 6-week BPRS total score, participants in the intervention group had significantly lower scores (lower symptom levels) than controls (intervention group, 1.95, (s.d. =0.57) $v$. control group 2.39 (s.d. $=0.87$ ); $P=0.003$ ), a mean difference of 0.63 points (95\% CI $0.59-0.87)$ representing an effect size (Cohen's $d$ ) of -0.48 . Significant differences were also observed on two BPRS subscales, thinking disturbance and hostile/suspiciousness (Table 3 ) with moderate effect sizes of -0.46 to -0.43 , respectively. Significant differences were also observed at 6 weeks on the Lehman quality of life scale (with an effect size of 0.43 ) and the GAF, openly rated by the prescribing psychiatrist, with a very large effect size of 1.70 .

Mixed-model longitudinal analyses were consistent with 6-week outcomes showing significantly greater improvement on the BPRS total score and the thinking disturbance and hostile/suspiciousness subscales as well as on the Lehman quality of life scale and the GAF (Table 3). There were no significant group[th][multi\&][th]time interactions on mixed models, and no significant differences in the number of days in chain at any time point.

Among the subgroup diagnosed with schizophrenia $(n=79$ with complete 6-week outcome data), significant differences were observed favouring the intervention group on the same four outcome measures as the total sample, but with larger effect sizes: total BPRS, Cohen's $d=-0.87, P<0.0001$; thinking disturbance subscale, Cohen's $d=-0.65, P=0.006$; hostile/suspiciousness subscale, Cohen's $d=-0.60, P=0.01$; and Lehman quality of life scale, Cohen's $d=0.65, P<0.004$

\section{Side-effects and adverse events}

The most common side-effect category among the intervention group were psychiatric symptoms, most likely reflecting the underlying illness. Only two of these symptom categories, asthenia/lassitude/increased fatigability and reduced duration of sleep, were documented for more than $10 \%$ of the intervention group UKU ratings (online Table DS1). Only three non-psychiatric symptoms 


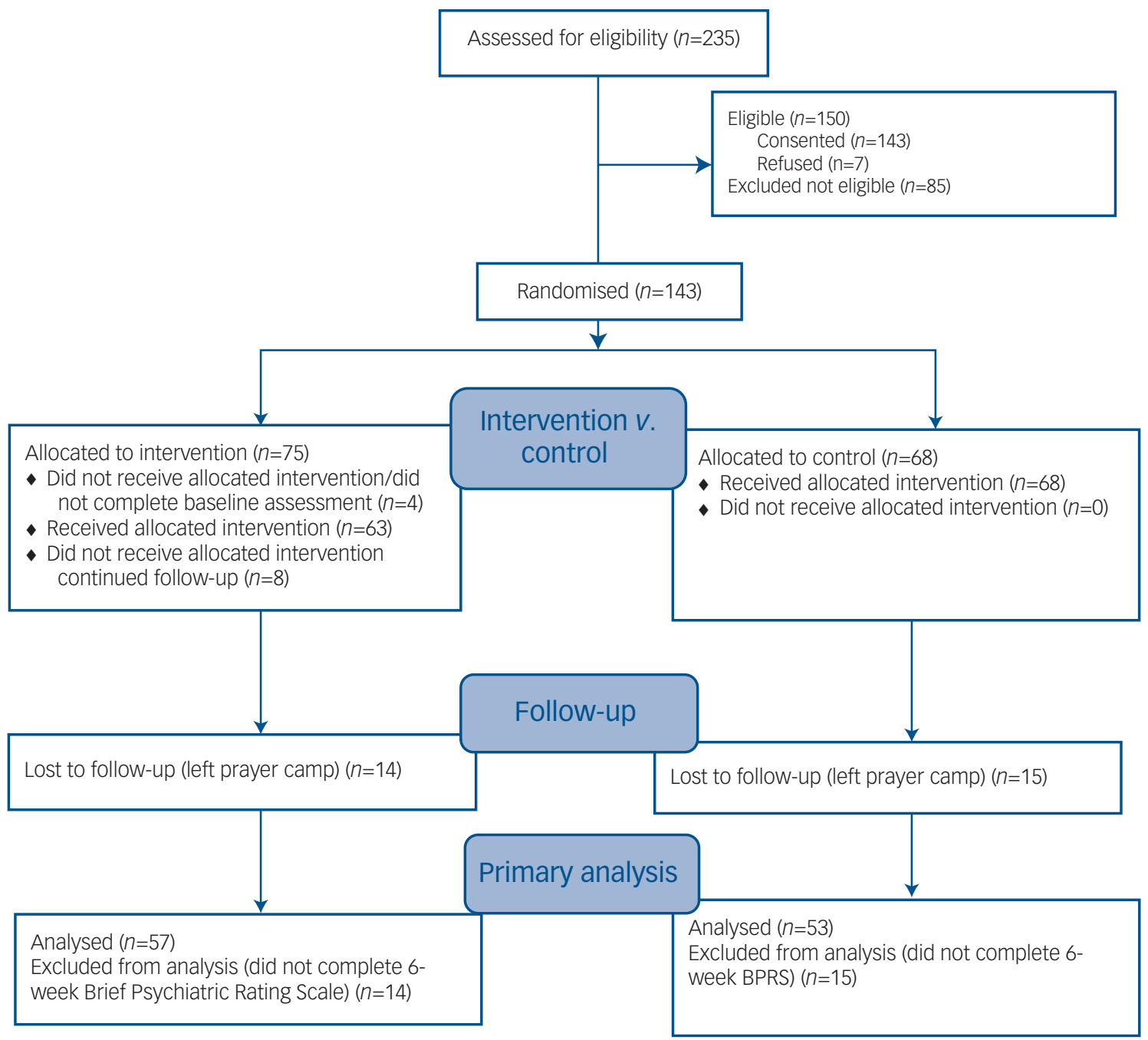

\section{Fig. 1 CONSORT 2010 flow diagram.}

BPRS, Brief Psychiatric Rating Scale.

were observed in more than 5\% of UKU ratings in this group: dystonia, tremor and increased salivation.

In terms of adverse events, there were no reports of suicide attempts and no admissions to hospital of research participants. There were no reports of other serious adverse events.

\section{Discussion}

\section{Main findings}

This RCT demonstrated significant additional benefits for a psychotropic drug intervention, with supporting psychiatric and nursing care, for patients with schizophrenia, mood disorders and other psychiatric conditions as compared with usual treatment in a large prayer camp in Ghana. This 'real-world' effectiveness study evaluated treatment for multiple disorders because the intervention being tested was 'pharmacological treatment' broadly conceived as introduced into a novel setting, a setting that could have attenuated the effectiveness of medication because of stresses of human rights abuses and stigmatisation.

Masked assessments with a commonly used measure of general psychiatric symptoms showed significant benefits at 6 weeks with a moderate effect size of 0.48 , along with significant benefits on subscales addressing thought disorder and violent/hostile behaviour, although not on the withdrawal/retardation or anxious/depression subscales. Gains in the latter two domains may have been more difficult to obtain or detect in 6 weeks or in the restrictive prayer camp environment in which many patients remained in chains and all had limited interactions with the world beyond the prayer camp. Significant benefits (effect size of 0.43 ) were also documented on a simple subjective self-report measure of global quality of life. Far larger group differences (effect size 1.70) were observed on the un-masked ratings on the GAF by the treating psychiatrist/residents, no doubt reflecting some degree of assessment bias since GAF raters were aware of whether or not each patient was taking medication as well as the objectives of the study. The 6-week findings on all of these measures were confirmed by longitudinal mixed-model analyses using data from all time points and replicated, with larger effects sizes, on the subgroup diagnosed with schizophrenia. Sideeffect data were only available from the intervention group but were identified at lower levels than have been documented in the published literature using the same UKU measure in a sample of patients treated with antipsychotics for the diagnosis of schizophrenia. ${ }^{22}$ 


\begin{tabular}{|c|c|c|c|c|c|c|c|}
\hline \multirow[b]{2}{*}{ Characteristic } & \multicolumn{2}{|c|}{ Group } & \multicolumn{2}{|c|}{ Group, $n$} & \multicolumn{3}{|c|}{ Statistics } \\
\hline & Intervention & Control & Intervention & Control & $\chi^{2 a}$ & $t$-test & $P$ \\
\hline Age, mean (s.d.) & $33.82(10.55)$ & $32.44(10.41)$ & 71 & 68 & & 0.78 & 0.44 \\
\hline Gender, $n$ (\%) & & & 71 & 68 & 0.13 & & 0.72 \\
\hline Men & $46(64.8)$ & $47(69.1)$ & & & & & \\
\hline Women & $25(35.2)$ & $21(30.9)$ & & & & & \\
\hline Marital status, $n$ (\%) & & & 71 & 68 & 0.47 & & 0.79 \\
\hline Never married & $56(78.9)$ & $52(76.5)$ & & & & & \\
\hline Married & $5(7.0)$ & $7(10.3)$ & & & & & \\
\hline Separated/widowed/divorced & $10(14.1)$ & $9(13.2)$ & & & & & \\
\hline Education, years, mean (s.d.) & $8.83(2.73)$ & $9.26(3.15)$ & 70 & 68 & & -0.86 & 0.39 \\
\hline Any children, yes: $n$ (\%) & $20(28)$ & $19(28)$ & 71 & 68 & 0.01 & & 0.98 \\
\hline Diagnosis, $n$ (\%) & & & 70 & 68 & & & \\
\hline Schizophrenia/schizoaffective & $58(82.9)$ & $53(77.9)$ & & & 0.61 & & 0.47 \\
\hline Bipolar (includes manic episodes) & $8(11.4)$ & $6(8.8)$ & & & 0.26 & & 0.61 \\
\hline Major affective disorder & $2(2.9)$ & $2(2.9)$ & & & $-^{a}$ & & 1.00 \\
\hline Alcohol use disorder & $1(1.4)$ & $4(5.9)$ & & & $\mathrm{a}^{\mathrm{a}}$ & & 0.20 \\
\hline Drug use disorder & $2(2.9)$ & $2(2.9)$ & & & $-^{a}$ & & 1.00 \\
\hline Other & 0 & $3(4.4)$ & & & $-^{a}$ & & 0.12 \\
\hline Global Assessment of Functioning, mean (s.d.) & $35.10(13.64)$ & $33.38(14.72)$ & 50 & 55 & & 0.62 & 0.54 \\
\hline Brief Psychiatric Rating Scale, mean (s.d.) & $2.58(0.81)$ & $2.78(0.99)$ & 69 & 66 & & -1.29 & 0.20 \\
\hline Withdrawal/retardation & $2.50(1.13)$ & $2.83(1.67)$ & 69 & 66 & & -1.34 & 0.18 \\
\hline Thinking disturbance & $3.29(1.52)$ & $3.36(1.57)$ & 67 & 61 & & -0.27 & 0.79 \\
\hline Anxious or depressed & $1.92(1.15)$ & $1.97(1.30)$ & 66 & 61 & & -0.23 & 0.82 \\
\hline Hostile/suspiciousness & $2.66(1.22)$ & $2.92(1.49)$ & 69 & 65 & & -1.13 & 0.26 \\
\hline Brief Symptom Inventory, mean (s.d.) & $1.03(0.90)$ & $1.07(0.91)$ & 57 & 51 & & -0.24 & 0.81 \\
\hline Patient Health Questionnaire (PHQ-9), mean (s.d.) & $0.61(0.64)$ & $0.56(0.63)$ & 71 & 68 & & 0.50 & 0.62 \\
\hline Lehman Quality of Life Interview, mean (s.d.) & 3.07 (1.92) & $2.72(1.95)$ & 71 & 68 & & 1.04 & 0.30 \\
\hline Days in chains (past 2 weeks), mean (s.d.) & $11.83(5.10)$ & $12.56(4.29)$ & 66 & 66 & & -0.89 & 0.38 \\
\hline
\end{tabular}

\section{Comparison with findings from other studies}

BPRS total score effect sizes are quite similar to the 0.51 effect size reported in a recent meta-analysis of second-generation antipsychotics in the treatment of schizophrenia ${ }^{24}$ based on 38 RCTs with 7323 participants. They are also similar to the effect size

\begin{tabular}{|c|c|c|c|}
\hline & $\begin{array}{l}\text { Intervention } \\
\text { group }\end{array}$ & $\begin{array}{l}\text { Control } \\
\text { group }\end{array}$ & Difference, \% \\
\hline Psychiatrist visits, ${ }^{a} n$ & 207 & 198 & \\
\hline Average visits per patient & 3.04 & 2.79 & \\
\hline \multicolumn{4}{|l|}{ Prescriptions, $n$ (\%) } \\
\hline Antipsychotics $^{b}$ & $179(86.5)$ & $31(15.7)$ & 70.8 \\
\hline Haloperidol & 67 (32.4) & $12(6.1)$ & 26.3 \\
\hline Olanzapine & $80(38.6)$ & $13(6.6)$ & 32.1 \\
\hline Risperidone & $13(6.3)$ & $3(1.5)$ & 4.8 \\
\hline Fluphenazine decanoate & $19(9.2)$ & $3(1.5)$ & 7.7 \\
\hline $\begin{array}{l}\text { Anticholinergics } \\
\text { (benztropine, } \\
\text { trihexyphenidyl) }\end{array}$ & $27(13.0)$ & $1(0.5)$ & 12.5 \\
\hline $\begin{array}{l}\text { Antidepressants } \\
\text { (fluoxetine, } \\
\text { amitriptyline) }\end{array}$ & $18(8.7)$ & $0(0)$ & 8.7 \\
\hline $\begin{array}{l}\text { Mood stabilisers } \\
\text { (carbamazepine) }\end{array}$ & $22(10.6)$ & $9(4.5)$ & 6.1 \\
\hline Anxiolytics (diazepam) & $3(1.4)$ & $6(3)$ & -1.6 \\
\hline \multicolumn{4}{|c|}{$\begin{array}{l}\text { a. Visits to a psychiatrist at which all prescriptions for psychotropic medication were } \\
\text { documented. } \\
\text { b. Average doses for antipsychotics. Haloperidol - intervention group: } 9.5[\text { th]mg (s.d. = } \\
\text { 4.0), control group: } 9.2[\text { th]mg (s.d. = } 2.04 \text { ); olanzapine }- \text { intervention group: } 10.7[\text { th]mg } \\
\text { (s.d. = 4.8), control group: } 8.8[\text { [th]mg (s.d. }=2.99 \text { ); risperidone - intervention group: } 5.6[\text { th] } \\
\text { mg (s.d. =6.0), control group: } 3.0[\text { [th]mg (s.d. =0.0); fluphenazine decanoate - interven- } \\
\text { tion group: } 35.4[\text { [th]mg (s.d. = 17.0), control group: } 25.0[\text { [th]mg (s.d. = 0.0). }\end{array}$} \\
\hline
\end{tabular}

averaging 0.50 observed in a meta-analysis of both psychopharmacological and psychotherapeutic treatments involving 21 different psychiatric disorders including 852 individual studies involving 137 [th] 126 participants. ${ }^{25}$ Thus, our study of pharmacotherapy within the potentially adverse environment of a prayer camp revealed not only statistically significant benefits, but effect sizes similar to those reported in controlled studies conducted in conventional clinical settings in high- and middle-income countries, with even larger effects in the subsample diagnosed with schizophrenia.

\section{Ethical issues}

It is notable that in spite of clear evidence of measurable clinical improvement, there was no associated reduction in days in chains, an issue of considerable clinical and human rights concern. On the one hand, it is possible that clinical improvement, although statistically significant, was not large enough to obviate the need for chains by prayer camp standards. Alternatively, decisions by prayer camp staff may have been based on criteria other than clinical status as measured by the BPRS.

The lack of significant effect of medication on chaining may reflect incomplete integration of the medical team into decisionmaking by prayer camp staff, who made all final decisions about chaining. Although the prophet, who founded and led the camp, and his staff welcomed the medical team and fully supported its clinical and research efforts, he was a believer in the religious not biomedical model of mental illness, and the collaboration might be best described as a co-location of complementary services rather than a full integration. Although joint meetings were conducted in which medical staff shared their perspectives on the care for people with mental illness and advocated for removing 


\begin{tabular}{|c|c|c|c|c|c|c|c|c|c|c|c|c|c|c|c|}
\hline \multirow[b]{2}{*}{ Measure and group } & \multicolumn{3}{|c|}{ Visit 1 (baseline) } & \multicolumn{3}{|c|}{ Visit 2 (2 weeks) } & \multicolumn{3}{|c|}{ Visit 3 (4 weeks) } & \multicolumn{3}{|c|}{ Visit 4 (6 weeks) } & \multirow[b]{2}{*}{ 6-week ES, $d$} & \multicolumn{2}{|c|}{$\begin{array}{c}\text { Mixed-model repeated } \\
\text { measures analysis }\end{array}$} \\
\hline & $n$ & Mean & $P$ & $n$ & Mean & $P$ & $n$ & Mean & $P$ & $n$ & Mean & $P$ & & $F$ (d.f.) & $P$ \\
\hline Total average BPRS & & & 0.20 & & & 0.048 & & & 0.07 & & & 0.003 & -0.48 & $6.70(1,189.3)$ & 0.01 \\
\hline Control & 66 & 2.78 & & 61 & 2.58 & & 58 & 2.31 & & 53 & 2.39 & & & & \\
\hline Intervention & 69 & 2.58 & & 61 & 2.26 & & 57 & 2.06 & & 57 & 1.95 & & & & \\
\hline BPRS, thinking disturbance & & & 0.79 & & & 0.66 & & & 0.04 & & & 0.019 & -0.46 & $5.02(1,191.3)$ & 0.026 \\
\hline Control & 61 & 3.36 & & 57 & 3.05 & & 56 & 2.93 & & 53 & 2.77 & & & & \\
\hline Intervention & 67 & 3.29 & & 61 & 2.92 & & 57 & 2.41 & & 57 & 2.06 & & & & \\
\hline BPRS, hostile/ suspiciousness & & & 0.26 & & & 0.017 & & & 0.12 & & & 0.016 & -0.43 & $6.43(1,187.1)$ & 0.012 \\
\hline Control & 65 & 2.92 & & 61 & 2.75 & & 58 & 2.26 & & 52 & 2.46 & & & & \\
\hline Intervention & 69 & 2.66 & & 59 & 2.20 & & 57 & 1.94 & & 56 & 1.87 & & & & \\
\hline BPRS, withdrawal/ retardation & & & 0.18 & & & 0.34 & & & 0.52 & & & 0.34 & -0.17 & $0.82(1,199.14)$ & 0.37 \\
\hline Control & 66 & 2.83 & & 61 & 2.65 & & 58 & 2.77 & & 52 & 2.51 & & & & \\
\hline Intervention & 69 & 2.50 & & 61 & 2.42 & & 57 & 2.63 & & 56 & 2.26 & & & & \\
\hline BPRS, anxious/depression & & & 0.82 & & & 0.78 & & & 0.55 & & & 0.28 & -0.16 & $0.20(1,157.02)$ & 0.65 \\
\hline Control & 61 & 1.97 & & 54 & 2.00 & & 54 & 1.60 & & 49 & 1.70 & & & & \\
\hline Intervention & 66 & 1.92 & & 60 & 1.93 & & 56 & 1.72 & & 56 & 1.50 & & & & \\
\hline $\mathrm{BSI}$, total score & & & 0.80 & & & 0.50 & & & 0.07 & & & 0.26 & 0.17 & $3.07(1,168.05)$ & 0.082 \\
\hline Control & 68 & 12.63 & & 66 & 12.51 & & 67 & 9.78 & & 64 & 9.89 & & & & \\
\hline Intervention & 71 & 13.24 & & 70 & 14.17 & & 66 & 13.92 & & 63 & 12.30 & & & & \\
\hline PHQ-9, total score & & & 0.62 & & & 0.64 & & & 0.11 & & & 0.25 & 0.18 & $2.55(1,1986.7)$ & 0.11 \\
\hline Control & 68 & 5.59 & & 66 & 6.08 & & 67 & 4.55 & & 64 & 4.71 & & & & \\
\hline Intervention & 71 & 6.13 & & 70 & 6.63 & & 66 & 6.21 & & 63 & 5.85 & & & & \\
\hline Lehman QOLI & & & 0.31 & & & 0.19 & & & 0.29 & & & 0.028 & 0.43 & $4.39(1,203.63)$ & 0.037 \\
\hline Control & 68 & 27.29 & & 66 & 28.17 & & 67 & 28.92 & & 64 & 29.67 & & & & \\
\hline Intervention & 71 & 30.59 & & 70 & 32.81 & & 66 & 32.79 & & 63 & 37.90 & & & & \\
\hline Days in chains & & & 0.37 & & & 0.31 & & & 0.07 & & & 0.38 & -0.17 & $1.55(1,258.5)$ & 0.21 \\
\hline Control & 66 & 12.56 & & 66 & 12.52 & & 60 & 12.37 & & 53 & 11.38 & & & & \\
\hline Intervention & 66 & 11.83 & & 66 & 11.67 & & 57 & 10.56 & & 54 & 10.37 & & & & \\
\hline GAF score, psychiatrist & & & 0.54 & & & 0.001 & & & $<0.0001$ & & & $<0.0001$ & 1.70 & $46.12(1,158.9)$ & $<0.0001$ \\
\hline Control & 55 & 33.38 & & 66 & 29.57 & & 53 & 36.06 & & 49 & 36.45 & & & & \\
\hline Intervention & 50 & 35.10 & & 70 & 45.17 & & 53 & 54.09 & & 48 & 60.63 & & & & \\
\hline
\end{tabular}


the chains in particular cases, final decisions about chaining were made solely by prayer camp staff (see online supplement DS1). Research staff did not demand elimination of prayer camp activities such as chaining and fasting because of concern that aggressive attempts to change practices would have disrupted the collaborative effort and precluded the opportunity to either offer treatment or conduct the research.

The design of this study posed an ethical challenge because of potentially abusive treatments included in standard prayer camp procedures. As noted above very effort was made to assure that the study provided health benefits to all residents in the sanitarium and that research procedures and research staff made every effort to reduce human rights abuses, both through education of staff and through case by case review and comment. There was neither endorsement nor legitimation of any abusive procedures.

Critical commentaries on the care provided in prayer camps, specifically in Ghana, have been harsh in their judgement of human rights violations, especially chaining, physical abuse, restraints on movement and involuntary fasting. These critiques have appeared in the medical literature, UN reports, ${ }^{6,26}$ and the popular press ${ }^{7}$ in recent years. At the same time, it is widely recognised that many people in Ghana and other low-income countries prefer non-medical approaches ${ }^{27}$ to mental health problems, strongly endorse the beliefs underlying such approaches, ${ }^{27}$ and continue to voluntarily seek them out. ${ }^{3}$ Some prayer camp services, such as church services and Bible study may provide valuable psychosocial support. There is also recent evidence from Ghana that many prayer camp leaders and medical professionals are becoming interested in expanding their collaboration. ${ }^{28}$ The positive results of this clinical trial provide evidence that substantial health benefits can result from such collaborations.

\section{Limitations}

This study has several methodological limitations. First, the study was only 6 weeks in duration. For the benefits identified here to translate into durable health improvements, treatment must be sustained past the period of prayer camp involvement through accessible out-patient services and a reliable medication supply. Second, the trial presented here was supported by a special allocation of medical and support staff and of medication. These resources, although accessible in principle, are not always available in Ghana. Sustained benefits ultimately depend on the availability of a broad range of both trained health professionals and prayer camp staff who are willing and eager to collaborate. Finally, our measurement of chaining only concerned the number of days in which any time was spent in chains and could not document reductions in the number of hours spent in chains each day. Future research and policy initiatives should seek a greater role for medical professionals in decisions about the management of this controversial intervention.

\section{Implications}

In spite of these limitations, this study is the first to rigorously demonstrate the clinical effectiveness of combining psychiatric care with traditional healing and/or religious practice in a prayer camp environment in a low-income country. Although, in this case, the observed clinical benefits did not lead to a reduction of days with time spent in chains, structural modification of the collaboration may allow the symptom improvements observed here to translate into reduced use, or elimination, of chaining. The study demonstrates the potential importance of attention to social context in the evaluation of pharmacotherapies in global mental health.

Faith healing camps command the trust of many people in Ghana. It would be impossible to activate enough hospital beds to provide care for people currently seeking help from these camps. What is needed is to transform them into humane healing environments, in part, by demonstrating that medication can make a difference in realms camp staff have believed to be exclusively spiritual. Although the results presented here support the possibility of creating such humane healing environments, the challenge of achieving this goal at a national level is likely to require government financial support for secure infrastructure, a continuous supply of medication, and trained healthcare professionals as well as oversight from the government of Ghana to prevent abuses.

A. Ofori-Atta, DClinPsy, Department of Psychiatry, University of Ghana, School of Medicine and Dentistry, Accra, Ghana; J. Attafuah, management consultant, Accra, Ghana; H. Jack, Harvard Medical School, Boston, Massachusetts, USA, and Institute of Psychiatry, Psychology, and Neuroscience, King's College London, UK; F. Baning, MBChB, Ghana Health Service, Accra, Ghana; R. Rosenheck, MD, Department of Psychiatry, Yale University, New Haven, Connecticut, USA

Correspondence: Robert Rosenheck, Department of Psychiatry, Yale Medical School, New Haven, Connecticut, USA. Email: robert.rosenheck@yale.edu

First Received 24 February 2017, final revision 18 July 2017, accepted 21 July 2017

\section{Funding}

Funded by a grant from the University of Ghana and an Unrestricted Grant from Enterprise Insurance Ghana Ltd. Clinical Staff and medications were provided by the Ghana Health Service.

\section{Acknowledgements}

We are deeply grateful to the staff and sanitarium residents of Mount Horeb Prayer Center for their collaboration in this endeavour. We would also like to thank consortium members: S. Asafo, B. D-Williams, K. Obeng, L. Gyima, E. Boachie-Yiadom, F. Torgbefu, and S. Addom. S. Mohammed from Yale University helped in the planning of the protocol and selection of measures for the study.

\section{Supplementary material}

Supplementary material is available online at https://doi.org/10. 1192/bjp.2017.12

\section{References}

1 World Health Organization. Ghana Country Summary. World Health Organization, Department of Mental Health and Substance Abuse, 2007.

2 Ofori-Atta A, Read UM, Lund C, Consortium MHRP. A situation analysis of mental health services and legislation in Ghana: challenges for transformation. Afr J Psychiatry (Johannesbg) 2010; 13: 99-108.

3 Ae-Ngibise K, Cooper S, Adiibokah E, Akpalu B, Lund C, Doku V, et al. 'Whether you like it or not people with mental problems are going to go to them': a qualitative exploration into the widespread use of traditional and faith healers in the provision of mental health care in Ghana. Int Rev Psychiatry 2010; 22: 558-67.

4 Appiah-Poku J, Laugharne R, Mensah E, Osei Y, Burns T. Previous help sought by patients presenting to mental health services in Kumasi, Ghana. Soc Psychiatry Psychiatr Epidemiol 2004; 39: 208-11.

5 Quinn N. Beliefs and community responses to mental illness in Ghana: the experiences of family carers. Int J Soc Psychiatry 2007; 53: 175-88.

6 Edwards J. Ghana's mental health patients confined to prayer camps. Lancet 2014; 383: 15-6.

7 Carey B. The Chains of Mental Illness in West Africa. New York Times; 2015 11 Oct.

8 Fosu GB. Women's orientation toward help-seeking for mental disorders. Soc Sci Med 1995; 40: 1029-40.

9 Lamensdorf Ofori-Atta AM, Linden W. The effect of social change on causal beliefs of mental disorders and treatment preferences in Ghana. Soc Sci Med 1995; 40: 1231-42. 
10 Ofori-Atta A, Cooper S, Akpalu B, Osei A, Doku V, Lund C, et al. Common understandings of women's mental illness in Ghana: results from a qualitative study. Int Rev Psychiatry 2010; 22: 589-98.

11 Stefanovics EA, Rosenheck RA, He H, Ofori-Atta A, Cavalcanti M, Chiles C. Medical student beliefs and attitudes toward mental illness across five nations. J Nerv Ment Dis 2016; 204: 909-15.

12 Stefanovics EA, He H, Cavalcanti M, Neto H, Ofori-Atta A, Leddy M, et al. Witchcraft and biopsychosocial causes of mental illness: attitudes and beliefs about mental illness among health professionals in five countries. J Nerv Ment Dis 2016; 204: 169-74

13 Overall J, Gorham D. Brief Psychiatric Rating Scale. Psychol Rep 1962; 10 799-812.

14 Mount Horeb Prayer Center. Mount Horeb Prayer Center, 2012 (http://cosmologicsmagazine.com/lauren-taylor-waiting-on-god-in-ghana/)

15 World Health Organization. The ICD-10 Classification of Mental and Behavioural Disorders: Clinical Descriptions and Diagnostic Guidelines. WHO, 1992.

16 Derogatis LR. Brief Symptom Inventory (BSI)-18. Administration, Scoring and Procedures Manual. NCS Pearson Inc, 2001.

17 Lowe B, Kroenke K, Herzog W, Grafe K. Measuring depression outcome with a brief self-report instrument: sensitivity to change of the Patient Health Questionnaire (PHQ-9). J Affect Disord 2004; 81: 61-6.

18 Lehman A. A quality of life interview for the chronically mentally ill. Eval Program Plann 1988; 11: 51-62.

19 Jones SH, Thornicroft G, Coffey M, Dunn G. A brief mental health outcome scale-reliability and validity of the Global Assessment of Functioning (GAF). Br J Psychiatry 1995; 166: 654-9.

20 Guy W. ECDEU Assessment Manual for Psychopharmacology-Revised Department of Health, Education, and Welfare. Public Health Service, Alcohol,
Drug Abuse, and Mental Health Administration, NIMH Psychopharmacology Research Branch, Division of Extramural Research Programs, 1976.

21 Lingjaerde $O$, Ahlfors UG, Bech P, Dencker SJ, Elgen K. The UKU side effect rating scale. A new comprehensive rating scale for psychotropic drugs and a cross-sectional study of side effects in neuroleptic-treated patients. Acta Psychiatr Scand Suppl 1987; 334: 1-100.

22 Lindstrom E, Lewander T, Malm U, Malt UF, Lublin H, Ahlfors UG. Patient-rated versus clinician-rated side effects of drug treatment in schizophrenia. Clinical validation of a self-rating version of the UKU Side Effect Rating Scale (UKU-SERS-Pat). Nord J Psychiatry 2001; 55 (suppl 44): 5-69.

23 Cohen J. Statistical Power Analysis for the Behavioral Sciences (2nd edn). Lawrence Erlbaum Associates, 1988.

24 Leucht S, Arbter D, Engel RR, Kissling W, Davis JM. How effective are second-generation antipsychotic drugs? A meta-analysis of placebo-controlled trials. Mol Psychiatry 2009; 14: 429-47.

25 Huhn M, Tardy M, Spineli LM, Kissling W, Förstl H, Pitschel-Walz G, et al. Efficacy of pharmacotherapy and psychotherapy for adult psychiatric disorders: a systematic overview of meta-analyses. JAMA PSychiatry 2014; 71: 706-15.

26 Mendez JE. Report of the Special Rapporteur on Torture and Other Cruel, Inhuman or Degrading Treatment or Punishment. OHCHR, 2016.

27 Gureje O, Nortje G, Makanjuola V, Oladeji BD, Seedat S, Jenkins R. The role of global traditional and complementary systems of medicine in the treatment of mental health disorders. Lancet Psychiatry 2015; 2: 168-77.

28 Arias D, Taylor L, Ofori-Atta A, Bradley EH. Prayer camps and biomedical care in Ghana: is collaboration in mental health care possible? PLoS One 2016; 11: e0162305 